\title{
ANALISA KINERJA MESIN PENGERING LAUNDRY ANTARA PEMAKAIAN TENAGA LISTRIK DENGAN PEMAKAIAN GAS LPG PADA INDUSTRI RUMAHAN
}

\author{
AMIR $^{1}$, ALI ROSYIDIN ${ }^{2}$ PUNGKI SATRIA $\mathbf{W}^{3}$ \\ Program Studi Teknik Mesin, Fakultas Teknik, Universitas Muhammadiyah Tangerang \\ Jl. Perintis Kemerdekaan I/33 Cikokol-Tangerang \\ Email.: ${ }^{1 .}$ amirduta815@gmail.com
}

\begin{abstract}
Abstrak
Dewasa ini kebutuhan akan mesin pengeringan pakaian yang praktis sangat diperlukan untuk berbagai kalangan pada saat musim penghujan dan untuk di daerah perkotaan yang padat akan penduduk, polusi udara yang kotor, debu, asap pabrik dan keterbatasan ruang untuk mengeringkan pakaian. Penelitian dilakukan di industri rumahan yang berada di kabupaten tangerang.Mesin pengering pakaian bekerja dengan siklus kompresi uap. Energi listrik yang digunakan untuk menggerakan kompresor dari mesin siklus kompresi uap,. Penelitian dilakukan dengan menvariasikan kondisi awal basah pakaian : (a) perasan tangan, (b) peras mesin cuci dan jumlah fan udara balik yang dipergunakan. Mesin pengering pakaian dengan sistem tenag listrik yang bekerja dengan baik. Untuk mengeringkan 20 pakaian hasil peras mesin cuci dengan menggunakan 2 fan udara balik, mesin pengering memerlukan waktu 70 menit. Untuk mengeringkan 20 pakaian hasil peras mesin cuci dengan menggunakan 1 fan udara balik, mesin pengering memerlukan waktu 90 menit, dan untuk mengeringkan 20 pakaian hasil peras tangan dengan menggunakan 2 fan udara balik, mesin pengering memerlukan waktu 150 menit.
\end{abstract}

Kata Kunci : Mesin Pengering Pakaian, listrik, gas

\section{Pendahuluan}

Dewasa ini cuaca di bumi semakin tidak menentu, dan dapat mengakibatkan curah hujan yang tinggi untuk daerah tertentu. Untuk mengeringkan pakaian sangat bergantung pada panas matahari dan cuaca yang cerah. Akibat tidak menentunya cuaca yang cerah memaksa setiap orang menjemur pakaian mereka di dalam ruangan yang tertutup dan lembab.

Pelaku-pelaku usaha dalam bidang bisnis laundry, berlomba-lomba memberikan pelayanan yang baik dan cepat pada saat melakukan pelayanan di musim penghujan. Permasalahan tersebut, membuat orang menciptakan mesin pengering pakaian yangdapat bekerja di musim penghujan,hemat energi dan ramah lingkungan. Pada saat ini sudah dikenal beberapa jenis mesin pengering pakaian, pengeringan dengan memanfaatkan panas matahari, pengering menggunakan gas LPG, mesin pengering dengan menggunakan listrik. Namun ada kekurangan dan kelebihan sendiri untuk mesin pengering pakaian tersebut.

Kelebihan pengering dengan menggunakan panas matahari adalah ramah lingkungan, dan panas matahari yang didapatkan gratis, , dapat menjemur pakaian dalam jumlah yang banyak tanpa batasan ruang, waktu yang dibutuhkan untuk mengeringkan pakaian yang banyak sama dan aman. Sedangkan kekurangnnya adalah tidak bisa mengeringkan pakaian pada saa.t hujan atau bergantung dengan cuaca, lamanya pada saat proses pengeringan dan keterbatasan waktu.

\section{Laundry}

Laundry adalah jasa pencucian pakaian kotor sampai dengan kering dan siap pakai, dalam arti pakaian yang semula dibawa ke jasa binatu/laundry dalam keadaan kotor dan saat diterima kembali oleh konsumen pemakai jasa laundry pakaian tersebut sudah siap digunakan kembali (sudah bersih, dalam keadaan rapi dan telah disetrika), yang mana penentuan tarifnya adalah berdasarkan jumlah kilogram baju yang di laundry. Akan tetapi dalam praktiknya jasa yang ditawarkan kemudian berkembang menjadi jasa cuci basah, cuci kering, cuci s/d setrika dan setrika saja

\section{Pengering}

Pengeringan adalah proses perpindahan massa air atau pelarut lainnya dari suatu zat padat atau semi padat dengan menggunakan penguapan. Proses ini seringkali merupakan tahap akhir proses prduksi sebelum dikemas atau dijual ke konsumen.

\section{Metode-Metode Dalam Pengringan Pakaian}

Seiring berkembangnya jaman banyak orang berlomba-lomba membuat trobosan baru dalam 
mengeringkan pakaian. Dewasa ini ada banyak metode-metode pengeringan pakaian baik secara alami maupun pengeringan menggunakan mesin pengering pakaian adapun pengeringan antara lain :

(a) menggunakan cahaya panas matahari,

(b) pengeringan pakaian dengan gaya sentrifugal,

(c) pengeringan pakaian menggunakan gas LPG,

(d) mesin pengering pakaian menggunakan elemen pemanas,

(e) pengeringan pakaian dengan metode dehumidifikasi

\section{Tenaga Listrik}

Energi listrik adalah energi yang bersumber dari muatan listrik yang dapat menimbulkan medan listrik statis atau bergeraknya elektron pada pengantar listrik (konduktor) atau ioan (positif/ negatif) pada zat cair atau gas. Listrik mempunyai satuan Ampere dengan simbol A dan tegangan listrik bersimbol $\mathrm{V}$ dengan satuan volt dengan ketetapan kebutuhan penggunaan daya listrik Watt yang diberi simbol W. Energi listrik bisa diciptakan oleh sumber engerti yang lain bahkan dapat memberikan energi yang nantinya bisa dikonversikan ke energi lain.

Hukum Ohm adalah suatu pernyataan bahwa besar arus listrik yang mengalir melalui sebuah penghantar selalu berbanding lurus dengan tegangan yang diterapkan kepadanya. Sebuah benda penghantar dikatakan mematuhi hukum Ohm apabila nilai resistansinya tidak bergantung terhadap besar dan polaritas beda potensial yang dikenakan kepadanya. Walaupun pernyataan ini tidak selalu berlaku untuk semua jenis penghantar, tetapi istilah "hukum" tetap digunakan dengan alasan sejarah

a. Secara matematis hukum Ohm diekspresikan dengan persamaan.

(Sumber:https://id.wikipedia.org/wiki/Hukum Ohm) Dimana

$$
\begin{aligned}
& \mathrm{V}=\text { Tegangan Listrik (Ampere) } \\
& \mathrm{I}=\text { Kuat Arus (Volt) } \\
& \mathrm{R}=\text { Hambatan Listrik (Ohm) }
\end{aligned}
$$

b. Rumus untuk mengetahui besar energi listrik yang digunakan adalah

c.

(Sumber:h

https://idschool.net/smp/fisika-smp/rumus-energiDimana dan-daya-listrik/)

$$
\begin{aligned}
& W=\text { Energi Listrik }(\mathrm{J}) \\
& V=\text { Tegangan Listrik (Volt) } \\
& \mathrm{i}=\text { Kuat arus (A) } \\
& \mathrm{t}=\text { Waktu (s) }
\end{aligned}
$$

\section{Tenaga Gas}

Gas adalah salah satu dari empat wujud dasar materi (lainnya adalah padat, cairan, dan plasma). Gas murni dapat tersusun dari atom (misalnya gas mulia seperti neon), molekul elemen yang tersusun dari satu jenis atom (misalnya oksigen), atau molekul senyawa yang tersusun dari berbagai macam atom (misalnya karbon dioksida). Campuran gas akan mengandung beragam gas murni seperti udara. Hal yang membedakan gas dari cairan dan padat adalah pemisahan partikel gas yang sangat besar. Pemisahan ini biasanya membuat gas tak berwarna menjadi tak terlihat oleh pengamatan manusia.

\section{METODOLOGI PENELITIAN}

Pengujian ini dilakukan di Mb@k Laundry alamat Perumahan Griya Asri Sukamanah 2 Rajeg Kabupaten Tangerang mulai melakukan penelitian pada 01 Agustus 2019 sampai 30 Agustus 2019. Penelitian dilakukan setiap hari jam kerja yaitu mulai jam 08.00 WIB sampai jam 15.00 WIB

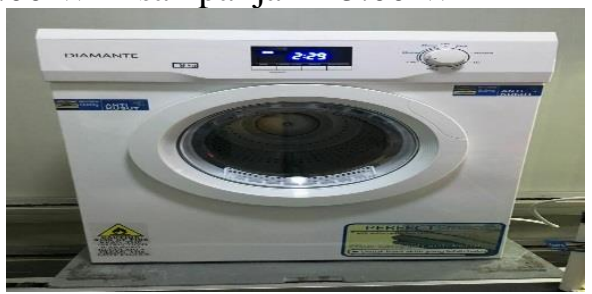

Gambar 2.1 Mesin pengering dengan tenaga listrik

Spesifikasi mesin pengering pakaian dengan tenaga listrik yaitu sebagai berikut :

a. Daya masuk 1700 watt

b. Tegangan $220-240 \mathrm{~V}$

c. Berat produk mesin pengering $30 \mathrm{~kg}$

d. Kapasitas 20 potong pakaian

e. Dimensi mesin pengering $595 \mathrm{~cm}$ X530 $\mathrm{cm}$ X840 $\mathrm{cm}$

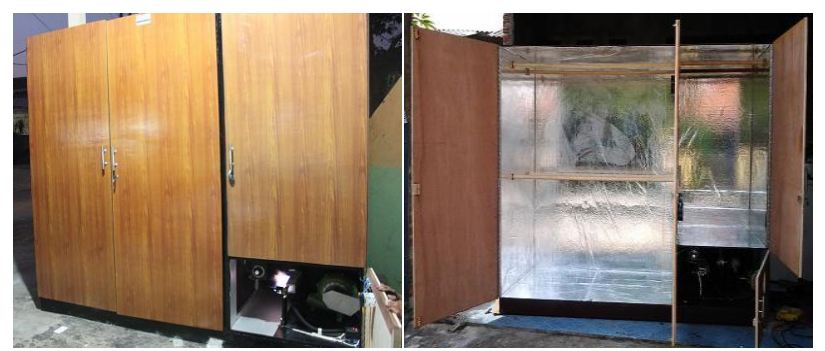

Gambar 2.2 Mesin pengering menggunakan tenaga gas 
Spesifikasi mesin pengering pakaian dengan tenaga gas berkapasitas 20 pakaian yaitu sebagai berikut :

a. Thermocontrol, yang berguna sebagai pengatur suhu sesuai keinginan (berkisari 0 - $120 \mathrm{C}$ )

b. Thermocouple

c. Timer otomatis untuk memudahkan aktifitas anda

d. Thermostat, Untuk pengaman suhu mesin

e. Variable Speed Blower (dapat disesuaikan kebutuhan)

f. 1 set selang + regulator

\section{Diagram Aliran Penelitian}

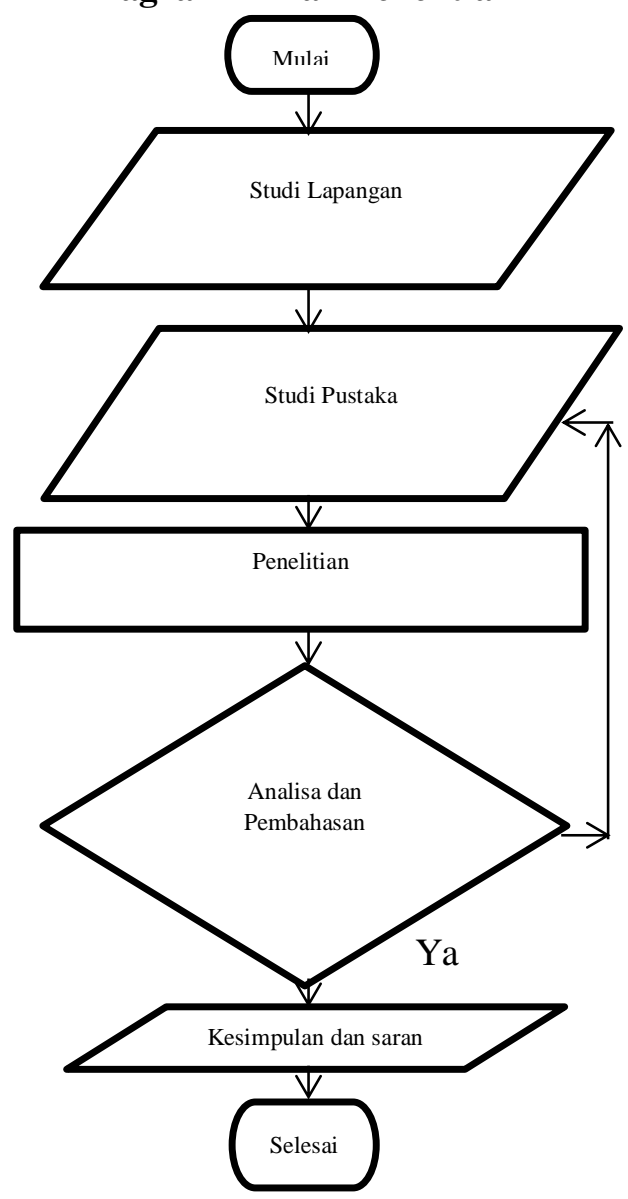

3. HASIL DAN PEMBAHASAN

Tabel 3.1 Data untuk hasil rata-rata peras mesin cuci 2 fan untuk 20 pakaian

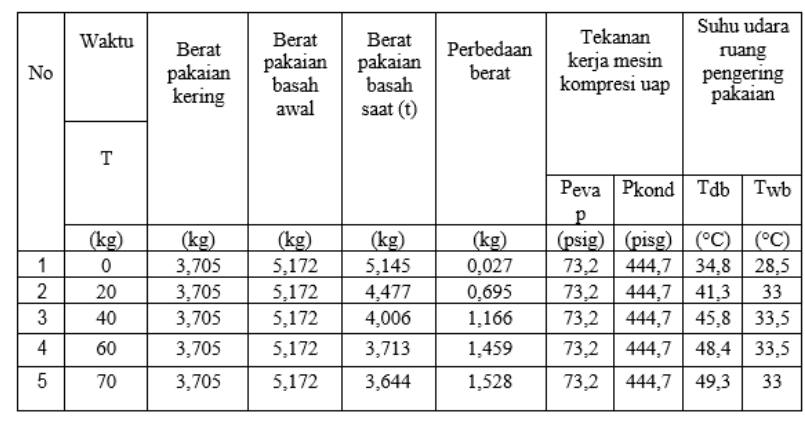

Tabel 3.2 Lanjutan data untuk hasil rata-rata peras mesin cuci 2 fan untuk20 pakaian

\begin{tabular}{|c|c|c|c|c|c|c|c|c|}
\hline \multirow{4}{*}{ No } & Waktu & \multicolumn{3}{|c|}{ Suhu udara setelah melewati } & \multirow{3}{*}{$\begin{array}{c}\text { Suhu } \\
\text { udara } \\
\text { melewat } \\
\text { i lemari } \\
\text { pengering }\end{array}$} & \multirow{2}{*}{\multicolumn{2}{|c|}{$\begin{array}{c}\text { Suhu } \\
\text { udara } \\
\text { masuk } \\
\text { evaporator }\end{array}$}} & \multirow{3}{*}{ I } \\
\hline & \multirow{2}{*}{$\mathrm{T}$} & evaporator & kompresor & kondensor & & & & \\
\hline & & $\mathrm{T}_{\text {evap }}$ & $\mathrm{T}_{\text {komp }}$ & $\mathrm{T}_{\mathrm{kond}}$ & & $T_{d b}$ & $\mathrm{~T}_{\mathrm{wb}}$ & \\
\hline & (menit) & $\left({ }^{\circ} \mathrm{C}\right)$ & $\left({ }^{\circ} \mathrm{C}\right)$ & $\left({ }^{\circ} \mathrm{C}\right)$ & $\mathrm{T}\left({ }^{\circ} \mathrm{C}\right)$ & $\left({ }^{\circ} \mathrm{C}\right)$ & $\left({ }^{\circ} \mathrm{C}\right)$ & (A) \\
\hline 1 & 0 & 19,7 & 31,6 & 66,1 & 36,8 & 28 & 28 & 4,6 \\
\hline 2 & 20 & 27,5 & 38,8 & 78,3 & 46,5 & 34 & 34,5 & 4,6 \\
\hline 3 & 40 & 27 & 39,6 & 80,2 & 50,3 & 34 & 34,5 & 4,6 \\
\hline 4 & 60 & 24,3 & 40,3 & 79,7 & 53,1 & 33,5 & 34 & 4,6 \\
\hline 5 & 70 & 22,9 & 39,6 & 78,2 & 52,5 & 33 & 33 & 4,6 \\
\hline
\end{tabular}

Tabel 3.3 Data untuk hasil rata-rata peras mesin cuci 1 fan untuk 20 pakaian

\begin{tabular}{|c|c|c|c|c|c|c|c|c|c|}
\hline \multirow[t]{3}{*}{ No } & \multirow{2}{*}{$\begin{array}{c}\text { Waktu } \\
\mathrm{t}\end{array}$} & \multirow[t]{2}{*}{$\begin{array}{c}\text { Berat } \\
\text { pakaian } \\
\text { kering }\end{array}$} & \multirow{2}{*}{$\begin{array}{c}\text { Berat } \\
\text { pakaian } \\
\text { basah } \\
\text { awal }\end{array}$} & \multirow{2}{*}{$\begin{array}{c}\text { Berat } \\
\text { pakaian } \\
\text { basah } \\
\text { saat }(\mathrm{t})\end{array}$} & \multirow[t]{2}{*}{$\begin{array}{c}\text { Perbedaan } \\
\text { berat }\end{array}$} & \multicolumn{2}{|c|}{$\begin{array}{c}\text { Tekanan } \\
\text { kerja mesin } \\
\text { kompresi uap }\end{array}$} & \multicolumn{2}{|c|}{$\begin{array}{l}\text { Suhu udara } \\
\text { ruang } \\
\text { pengering } \\
\text { pakaian }\end{array}$} \\
\hline & & & & & & $P_{\text {evap }}$ & $P_{\text {kond }}$ & $\mathrm{T}_{\mathrm{db}}$ & $\mathrm{T}_{\mathrm{wb}}$ \\
\hline & (menit) & (kg) & $(\mathrm{kg})$ & (kg) & (kg) & (psig) & (pisg) & $\left({ }^{\circ} \mathrm{C}\right)$ & $\left({ }^{\circ} \mathrm{C}\right)$ \\
\hline 1 & 0 & 3,704 & 5,172 & 5,199 & 0,027 & 73,2 & 444,7 & 31,3 & 27,5 \\
\hline 2 & 20 & 3,704 & 5,172 & 4,628 & 0,544 & 73,2 & 444,7 & 39,7 & 31,5 \\
\hline 3 & 40 & 3,704 & 5,172 & 4,199 & 0,973 & 73,2 & 444,7 & 41,6 & 32,5 \\
\hline 4 & 60 & 3,704 & 5,172 & 3,934 & 1,238 & 73,2 & 444,7 & 45,2 & 33 \\
\hline 5 & 80 & 3,704 & 5,172 & 3,739 & 1,433 & 73,2 & 444,7 & 48,9 & 33 \\
\hline 6 & 90 & 3,704 & 5,172 & 3,642 & 1,53 & 73,2 & 444,7 & 48,3 & 31,5 \\
\hline
\end{tabular}

Tabel 3.4 Data untuk hasil rata-rata peras tangan 2 fan untuk 20 pakaian

\begin{tabular}{|c|c|c|c|c|c|c|c|c|c|}
\hline \multirow[t]{3}{*}{ No } & \multirow{2}{*}{$\begin{array}{c}\text { Waktu } \\
\text { (t) }\end{array}$} & \multirow[t]{2}{*}{$\begin{array}{c}\text { Berat } \\
\text { pakaian } \\
\text { kering }\end{array}$} & \multirow[t]{2}{*}{$\begin{array}{c}\text { Berat } \\
\text { pakaian } \\
\text { basah } \\
\text { awal }\end{array}$} & \multirow[t]{2}{*}{$\begin{array}{c}\text { Berat } \\
\text { pakaian } \\
\text { basah } \\
\text { saat }(t)\end{array}$} & \multirow[t]{2}{*}{$\begin{array}{c}\text { Perbedaan } \\
\text { berat }\end{array}$} & \multicolumn{2}{|c|}{$\begin{array}{c}\text { Tekanan } \\
\text { kerja mesin } \\
\text { kompresi uap }\end{array}$} & \multicolumn{2}{|c|}{$\begin{array}{l}\text { Suhu udara } \\
\text { ruang } \\
\text { pengering } \\
\text { pakaian }\end{array}$} \\
\hline & & & & & & $P_{\text {evap }}$ & $P_{\text {kond }}$ & $\mathrm{T}_{\mathrm{db}}$ & $\mathrm{T}_{\mathrm{w} b}$ \\
\hline & (menit) & (kg) & (kg) & (kg) & (kg) & (psig) & (pisg) & $\left({ }^{\circ} \mathrm{C}\right)$ & $\left({ }^{\circ} \mathrm{C}\right)$ \\
\hline 1 & 0 & 3,659 & 8,386 & 8,386 & 0 & 73,2 & 444,7 & 37,4 & 28,5 \\
\hline 2 & 20 & 3,659 & 8,386 & 7,165 & 1,221 & 73,2 & 444,7 & 44,1 & 33,5 \\
\hline 3 & 40 & 3,659 & 8,386 & 6,212 & 2,174 & 73,2 & 444,7 & 43,7 & 34 \\
\hline 4 & 60 & 3,659 & 8,386 & 5,48 & 2,906 & 73,2 & 444,7 & 42,6 & 34,5 \\
\hline 5 & 80 & 3,659 & 8,386 & 4,681 & 3,705 & 73,2 & 444,7 & 48 & 35,5 \\
\hline 6 & 100 & 3,659 & 8,386 & 4,118 & 4,268 & 73,2 & 444,7 & 51,1 & 34,5 \\
\hline 7 & 120 & 3,659 & 8,386 & 3,819 & 4,567 & 73,2 & 444,7 & 50,2 & 34 \\
\hline 8 & 140 & 3,659 & 8,386 & 3,667 & 4,719 & 73,2 & 444,7 & 54,9 & 34 \\
\hline 9 & 150 & 3,659 & 8,386 & 3,639 & 4,747 & 73,2 & 444,7 & 48,1 & 33,5 \\
\hline
\end{tabular}


Tabel 3.5 Lanjutan data untuk hasil rata-rata peras tangan 2 fan untuk 20 pakaian

\begin{tabular}{|c|c|c|c|c|c|c|c|c|}
\hline \multirow{4}{*}{ No } & \multirow{3}{*}{$\begin{array}{c}\text { Waktu } \\
\mathrm{t}\end{array}$} & \multicolumn{3}{|c|}{ Suhu udara setelah melewati } & \multirow{3}{*}{$\begin{array}{c}\text { Suhu } \\
\text { udara } \\
\text { melewati } \\
\text { lemari } \\
\text { pengering }\end{array}$} & \multirow{2}{*}{\multicolumn{2}{|c|}{$\begin{array}{l}\text { Suhu udara } \\
\text { masuk } \\
\text { evaporator }\end{array}$}} & \multirow{3}{*}{ I } \\
\hline & & \multirow{2}{*}{\begin{tabular}{|c|} 
evaporator \\
$\mathrm{T}_{\text {evap }}$ \\
\end{tabular}} & \multirow{2}{*}{$\begin{array}{c}\text { Kompresor } \\
\mathrm{T}_{\text {komp }}\end{array}$} & \multirow{2}{*}{$\begin{array}{c}\text { kondensor } \\
\mathrm{T}_{\text {kond }}\end{array}$} & & & & \\
\hline & & & & & & $T_{d b}$ & $\mathrm{~T}_{\mathrm{wb}}$ & \\
\hline & (menit) & $\left({ }^{\circ} \mathrm{C}\right)$ & $\left({ }^{\circ} \mathrm{C}\right)$ & $\left({ }^{\circ} \mathrm{C}\right)$ & $\mathrm{T}\left({ }^{\circ} \mathrm{C}\right)$ & $\left({ }^{\circ} \mathrm{C}\right)$ & $\left({ }^{\circ} \mathrm{C}\right)$ & (A) \\
\hline 1 & 0 & 21,2 & 32,2 & 58,6 & 36,1 & 28 & 28,5 & 4,6 \\
\hline 2 & 20 & 28,7 & 38,6 & 71,3 & 44,3 & 34 & 35 & 4,6 \\
\hline 3 & 40 & 27,2 & 40 & 75,1 & 46,4 & 35 & 36 & 4,6 \\
\hline 4 & 60 & 29 & 40,3 & 73,7 & 49,7 & 35 & 36 & 4,6 \\
\hline 5 & 80 & 29,3 & 39,9 & 75,6 & 47,7 & 35 & 36 & 4,6 \\
\hline 6 & 100 & 28,3 & $4 \overline{0,2}$ & 81,7 & 49,8 & 34,5 & 35 & 4,6 \\
\hline 7 & 120 & 27,7 & 40,8 & 78,4 & 53,4 & 34 & 34,5 & 4,6 \\
\hline 8 & 140 & 26,7 & 40,6 & 79,6 & 53,9 & 34 & 34,5 & 4,6 \\
\hline 9 & 150 & 25,2 & 39,2 & 77,9 & 53 & 32,5 & 33 & 4,6 \\
\hline
\end{tabular}

Tabel 3.6 Data pengeringan 20 pakaian peras mesin cuci dengan pengering gas lpg

\begin{tabular}{|c|c|c|c|c|c|c|}
\hline Waktu & \multicolumn{5}{|c|}{ Berat pakaian(kg) } & \multicolumn{2}{c|}{$\begin{array}{c}\text { Suhu Udara Area } \\
\text { Penjemuran } \\
\text { Pakaian }\end{array}$} \\
\hline $\begin{array}{c}\text { (menit) } \\
\text { (merat }\end{array}$ & $\begin{array}{c}\text { Bakaian } \\
\text { kering }\end{array}$ & $\begin{array}{c}\text { Berat } \\
\text { pakaian } \\
\text { basah awal }\end{array}$ & $\begin{array}{c}\text { Berat pakaian } \\
\text { basah saat }(\mathrm{t})\end{array}$ & $\begin{array}{c}\text { Perbedaan } \\
\text { berat }\end{array}$ & $\begin{array}{c}\mathrm{T}_{\text {db }} \\
\left({ }^{\circ} \mathrm{C}\right)\end{array}$ & $\begin{array}{c}\mathrm{T}_{\mathrm{wb}} \\
\left({ }^{\circ} \mathrm{C}\right)\end{array}$ \\
\hline 0 & 3,715 & 5,235 & 5,235 & 0 & 32,6 & 24,5 \\
\hline 20 & 3,715 & 5,235 & 4,32 & 0,915 & 33,5 & 22,5 \\
\hline 40 & 3,715 & 5,235 & 3,88 & 1,355 & 34,6 & 22,5 \\
\hline 60 & 3,715 & 5,235 & 3,878 & 1,357 & 35,3 & 26,5 \\
\hline 80 & 3,715 & 5,235 & 3,655 & 1,58 & 35 & 27 \\
\hline 100 & 3,715 & 5,235 & 3,61 & 1,625 & 34,2 & 27,5 \\
\hline
\end{tabular}

Tabel 3.7 Data pengeringan 20 pakaian peras tangan dengan pengering gas lpg

\begin{tabular}{|c|c|c|c|c|c|c|}
\hline Waktu & \multicolumn{5}{|c|}{ Berat pakaian(kg) } & \multicolumn{2}{|c|}{$\begin{array}{c}\text { Suhu Udara Area } \\
\text { Penjemuran Pakaian }\end{array}$} \\
\hline (menit) & $\begin{array}{c}\text { Berat } \\
\text { pakaian } \\
\text { kering }\end{array}$ & $\begin{array}{c}\text { Berat } \\
\text { pakaian } \\
\text { basah awal }\end{array}$ & $\begin{array}{c}\text { Berat pakaian } \\
\text { basah saat (t) }\end{array}$ & $\begin{array}{c}\text { Perbedaan } \\
\text { berat }\end{array}$ & $\begin{array}{c}\mathrm{T}_{\mathrm{db}} \\
\left({ }^{\circ} \mathrm{C}\right)\end{array}$ & $\begin{array}{c}\mathrm{T}_{\mathrm{wb}} \\
\left({ }^{\circ} \mathrm{C}\right)\end{array}$ \\
\hline 0 & 3,7 & 8,295 & 8,295 & 0 & 30,6 & 31 \\
\hline 20 & 3,7 & 8,295 & 7,45 & 0,845 & 31,7 & 30 \\
\hline 40 & 3,7 & 8,295 & 6,695 & 1,6 & 32,6 & 31 \\
\hline 60 & 3,7 & 8,295 & 6,155 & 2,14 & 31,3 & 28,5 \\
\hline 80 & 3,7 & 8,295 & 5,83 & 2,465 & 31,1 & 31,5 \\
\hline 100 & 3,7 & 8,295 & 5,4 & 2,895 & 33,4 & 31,5 \\
\hline 120 & 3,7 & 8,295 & 4,87 & 3,425 & 32,9 & 30,5 \\
\hline 140 & 3,7 & 8,295 & 4,52 & 3,775 & 35,5 & 32,5 \\
\hline 160 & 3,7 & 8,295 & 4,16 & 4,135 & 35,7 & 31,5 \\
\hline 180 & 3,7 & 8,295 & 3,905 & 4,39 & 34,5 & 33,5 \\
\hline 200 & 3,7 & 8,295 & 3,76 & 4,535 & 34,8 & 31,5 \\
\hline 220 & 3,7 & 8,295 & 3,665 & 4,63 & 35,7 & 32 \\
\hline
\end{tabular}

\section{Analisa Menghitung massa air yang menguap} dari pakaian ( $\left.\dot{\mathbf{m}}_{\text {air }} \mathbf{1}\right)$

Massa air yang menguap dari pakaian (mair1) dapat dihitung menggunakan persamaan untuk 20 pakaian peras peras tangan menggunakan 2 fan pada menit ke 150 adalah sebagai berikut

$$
\begin{aligned}
M_{\text {airl }} & =\text { BPBA-BPBSt } m_{\text {airl }} \\
& =(8,386-3,639) \\
& =4,747 \mathrm{Kg}_{\text {air }}
\end{aligned}
$$

Kemampuan mesin pengering untuk menguapkan massa air ( $\left.\dot{\mathrm{m}}_{\text {air }}\right)$

$$
\begin{gathered}
=4,747(\mathrm{~kg}) 2,5(\mathrm{jam}) \\
=1,89 \mathrm{~kg} / \mathrm{jam}
\end{gathered}
$$

\section{KESIMPULAN}

Berdasarkan rumusan masalah pada penelitian ini penulis dapat menarik kesimpulan bahwa:

1. Waktu yang diperlukan untuk mengeringkan 20 pakaian dengan kondisi awal hasil peras mesin cuci dengan menggunakan 2 fan udara balik mesin pengering memerlukan waktu 70 menit, untuk mengeringkan 20 pakaian dengan kondisi awal hasil peras mesin cuci dengan menggunakan 1 fan udara balik mesin pengering memerlukan waktu 90 menit, dan untuk mengeringkan 20 pakaian dengann kondisi awal hasil peras tangan dengan menggunakan 2 fan udara balik mesin pengering memerlukan waktu 150 menit

2. Mesin pengering pakaian menggunakan tenaga listrik dibuat dan bekerja dengan baik, dengan kondisi awal suhu di dalam lemari pengering yaitu suhu udara bola kering sekitar $55,1^{\circ} \mathrm{C}$ dan suhu udara bola basah sekitar $30^{\circ} \mathrm{C}$

\section{DAFTAR PUSTAKA}

Balioglu,et al., 2013, "Heat Pump Laundri Dryer S Machine”, Patent Aplication Publication, Pub. No : US2013/0047456A1.

Beers, et al., 2013, "Apparatus and Method for Refrigeration Cycle Capacity Enhancement", Patent Aplication Publication, Pub. No : US 8,601,717 B2

Bernando Zakaria, Ambarita Himsar. "Rancang Bangun Kompresor dan Pipa Kapiler utuk Mesin Pengering Pakaian Sistem Pompa Kalor dengan Daya 1 PK’. Jurnal Fakultas. Teknik Mesin USU, vol 9, No 1 (2014) : jurnal e- Dinamis

Goldberg, et al., 2005, "Heat Pump Clothes Dryer", Patent Aplication Publication, Pub. No: US 2005/0066538 A1.

Koestoer Artono Raldi., 2002. "Perpindahaan Kalor Untuk Mahasiswa Teknik". Jakarta: Penerbit Salemba Teknika.

Johan Budi Harjanto, 2008, "Penuntun Praktikum Teknologi Perlengkapan Mesin Diesel" Vol 1. Restu Agung, Jakarta.

Kristanto, 2002, "Bahan Bakar Pada Motor Diesel Sistem Injeksi Langsung”. jurnal Teknik Mesin UK Petra,Vol 4. 
Johan Budi Harjanto, 2008, "Penuntun Praktikum Teknologi Perlengkapan Mesin Diesel" Vol 1. Restu Agung, Jakarta.

Kristanto, 2002, "Bahan Bakar Pada Motor Diesel Sistem Injeksi Langsung”. jurnal Teknik Mesin UK Petra,Vol 4.

Cengel A. Yunus. 2004. "Heat Transfer a practical Approach". Singapore: Mc.Graw Hill

Dinh, 1994, "Closed-loop Drying Process and System,

Patent Aplication Publication," Pub. No : 5,343,632.

Goldberg, et al., 2005, "Heat Pump Clothes Dryer, Patent Aplication Publication," Pub. No: US 2005/0066538 A1.

Koestoer Artono Raldi., 2002. "Perpindahaan Kalor Untuk Mahasiswa Teknik". Jakarta: Penerbit Salemba Teknika

Kurniandy Wijaya, Purwadi PK (2016). "Mesin Pengering Handuk Dengan Energi Listrik". Jurnal Fakultas Teknik Mesin UNS, Vol 15, No 2 (2016) : MEKANIKA

Lentz, 2008, "Dehumidifier Clothes Dryer Apparatus", Patent Aplication Publication, Pub. No : US $7,458,171 \mathrm{~B} 1$.

Maruca, 2007, "Low Temperature Clothes Dryer, Patent Aplication Publication”, Pub. No : US 7,191,546 B2.

PK Purwadi, Wibowo Kusbandono, "Mesin Pengering Baju Energi Listrik dengan Daya 800 Watt."

Prabowo, Ardy. 2017. "Mesin Pengering Pakaian Sistem Tertutup dengan Menggunakan Daya Listrik 1122 watt". Yogyakarta : Universitas Sanata Dharma.

Purwadi PK (2017). "Mesin Pengering Kapaitas Lima Puluh Baju Sistem Tertutup.” Jurnal Teknik Mesin, Fakultas Sains dan Teknologi, Universitas Sanata Dharma, Vol 16, No 2 (2017).

Setyawan Bagus, Arif Irfa'i Moch (2015). “Rancang Bangun Pengering Pakaian Kapasitas $10 \mathrm{KG}$ Berdaya 380 Watt”. Jurnal Fakultas Teknik Mesin Universitas Negeri Surabaya, Vol 02, No 02 (2015).

Anonim,2012, What Type Of Dehumidifier Do Ineed? Desiccant or Refrigerant, http://dehumidiferrental.co.uk/2012/12/14/what-typeofdehumidifier-doi-need-desiccant-orrefrigerant/

Harriman L., 1989, The Dehumidification Handbook (Edisi 2, Editor Harriman III, L. G.)

http://webdh.munters.com/Webdh/BrochureUploads /Munters\%20DH\%0handbook.pdf 